\title{
Laparoscopic cholecystectomy with indocyanine green fluorescence in patient with situs inversus totalis
}

\author{
Flavio Tirelli, Michele Grieco, Alberto Biondi, Francesco Belia, Roberto Persiani \\ Department of General Surgery, Fondazione Policlinico Universitario "A. Gemelli" IRCCS, Roma - Università Cattolica del Sacro \\ Cuore, Rome 00168, Italy.
}

Correspondence to: Flavio Tirelli, MD, Department of General Surgery, Fondazione Policlinico Universitario "A. Gemelli" IRCCS, Roma - Università Cattolica del Sacro Cuore. L.go A. Gemelli 8, Rome 00168, Italy. E-mail: tirelliflavio@gmail.com

How to cite this article: Tirelli F, Grieco M, Biondi A, Belia F, Persiani R. Laparoscopic cholecystectomy with indocyanine green fluorescence in patient with situs inversus totalis. Mini-invasive Surg 2021;5:15. https://dx.doi.org/10.20517/2574-1225.2021.04

Received: 13 Jan 2021 First Decision: 10 Feb 2021 Revised: 22 Feb 2021 Accepted: 8 Mar 2021 Available online: 8 Apr 2021

Academic Editor: Giulio Belli Copy Editor: Xi-Jun Chen Production Editor: Xi-Jun Chen

\begin{abstract}
Situs Viscerum Inversus (SVI) is a rare autosomal recessive disease. Because of this particular anatomy, it could be challenging for the surgeon to perform any abdominal procedure, including laparoscopic cholecystectomy. In these situations, indocyanine green fluorescence cholangiography can be essential. A 29-year-old female with documented situs viscerum inversus totalis underwent laparoscopic cholecystectomy with a four-trocar technique. Switching the vision to the near-infrared camera, which elicited the indocyanine green molecules, the surgeon could easily identify the common bile duct and the cystic duct. Switching back to the normal vision, the operator completed the dissection. The described procedure is still challenging due to the "mirror effect" and the uncommon position of the surgical instruments, especially for right-handed surgeons. Indocyanine green fluorescence angiography can help the surgeon identify the structures in cases of non-regular anatomy such as this.
\end{abstract}

Keywords: Situs inversus totalis, indocyanine green fluorescence, cholecystectomy

\section{INTRODUCTION}

Situs Viscerum Inversus (SVI) is a rare autosomal recessive condition which affects from 1:10,000 to 1:20,000 live births ${ }^{[1]}$. Kartagener's syndrome takes place when situs inversus, chronic sinusitis, and bronchiectasis occur together. Two variants are described: situs viscerum inversus partialis (involves thoracic or abdominal organs alone) and situs viscerum inversus totalis (involves both thoracic and 
abdominal organs $)^{[2]}$. Because of this particular anatomy, it could be challenging for the surgeon to perform any abdominal procedure, including laparoscopic cholecystectomy ${ }^{[3]}$. The "mirror image" is critically confusing, especially during the dissection of the Calot's triangle. In these situations, indocyanine green fluorescence cholangiography can be essential. It can allow highlighting and safely preserving all the biliary structures $^{[4,5]}$.

\section{CASE REPORT}

A 29 -year-old female, BMI $24.2 \mathrm{~kg} / \mathrm{m}^{2}$, was admitted to the authors' institution with diagnosed symptomatic presence of stones in the gallbladder with several episodes of epigastric pain, nausea, and vomiting. Medical history showed Kartagener's syndrome (DNAH5 gene mutation) with documented situs viscerum inversus totalis, bronchiectasis, and recurrent respiratory infections (the last episode occurring 18 months before the surgery). During a hospitalization in another institution due to bronchopneumonia, the patient underwent CT scan that showed gallbladder stones. Before the surgery, the patient underwent abdomen ultrasound and MRI as well.

The patient underwent laparoscopic cholecystectomy with a four-trocar technique. The operating surgeon was on the right side of the patient and the assistant was between the patient's legs. First, a 12-mm trocar was placed in the sub-umbilical portion. After inducing the pneumoperitoneum, three 5 - $\mathrm{mm}$ trocars were placed in the epigastrium, mesogastrium, and left flank, respectively. A diagnostic laparoscopy confirmed the SVI. Twenty-five milligrams of indocyanine green were diluted into $10 \mathrm{~mL}$ of sterile normal saline, and a bolus of $0.2 \mathrm{mg} / \mathrm{kg}$ was injected intravenously by the anesthesiologist $1 \mathrm{~h}$ before the surgery.

During the procedure, the operating surgeon started the dissection of the Calot's triangle by means of a diathermy hook. Switching the vision to the near-infrared camera, which elicited the indocyanine green molecules, the surgeon could easily identify the common bile duct and the cystic duct. Switching back to the normal vision, the operator completed the dissection. After being isolated, the cystic duct and the cystic artery were clipped, cut, and a retrograde cholecystectomy was performed with no difficulties. The operation took $74 \mathrm{~min}$ without intraoperative complications. The patient was discharged on Postoperative Day 2 uneventfully. The final pathology confirmed calculous cholecystitis.

\section{DISCUSSION}

The described procedure is still challenging due to the "mirror effect" and the uncommon position of the surgical instruments. For right-handed surgeons, the use of the non-dominant hand to perform the dissection could be challenging. Because of this, surgeons should reflect, first, on the trocars position. Some authors described a simple mirror trocar's position to perform this surgery ${ }^{[6]}$, but we suggest reconsidering this simplification for right-handed surgeons and rethinking the use of the instruments. As described in a recent review ${ }^{[7]}$, there is no standard technique to approach this uncommon orientation. Differently from what is described in other paper ${ }^{[3,7,8]}$, our equipment was composed by a surgeon and an assistant, and they decided the best port placement that allows the surgeon to perform the dissection with the right hand, having full control of the instrument and completely relying on the assistant for the necessary tractions on the gallbladder to reach the critical view of safety. By this, we tried to avoid the risk of vascular or biliary injury possibly due to the uncommon anatomy.

Thus, the patient's position was halfway between a mirrored "French" and "American" position because the patient was placed in a lithotomy position but with the surgeon on the patient's right and the assistant between the patient's legs. The surgeon's 5-mm operating trocar was placed midline, between the 5-mm one in the epigastrium and the $12-\mathrm{mm}$ one in the navel. The surgeon was right-handed and used the trocar in 
the epigastrium to pull the bottom of the gallbladder upward and the trocar in the mesogastrium to perform the monopolar hook dissection. The assistant, on the other hand, was positioned between the legs to permit holding the scope with the left hand and helping with the right hand the surgeon pulling the infundibulum of the gallbladder outwards. This position allowed the surgeon to obtain the best possible angle to perform a correct dissection of the gallbladder, with easy preparation of the cystic duct and the cystic artery. The administration of ICG (indocyanine green) was carried out about $1 \mathrm{~h}$ before the surgery and not previously because, in our department, we try to reduce hospital stays as much as possible we generally hospitalize patients for this type of surgery on the same day of the operation. As suggested by Tebala et al. ${ }^{\left[{ }^{[]]}\right.}$, ICG injection could be performed the day before the surgery in order to reach an optimal concentration in the bile, but there is no clear evidence in the literature that the administration of ICG $1 \mathrm{~h}$ before surgery is not already sufficient. This case demonstrated that administration $1 \mathrm{~h}$ before surgery could be sufficient, and the images in the video prove it. Indocyanine green fluorescence angiography can help the surgeon identify the structures in cases of non-regular anatomy such as this. In conclusion, in patients with SVI, laparoscopic cholecystectomy can be safely performed and ICG fluorescence can be helpful for identifying anatomical structures.

\section{DECLARATIONS}

\section{Authors' contributions}

Conception and design: Tirelli F, Grieco M, Biondi A, Belia F, Persiani R

Manuscript writing: Tirelli F, Belia F

Video editing: Grieco M, Tirelli F, Belia F

Final approval of manuscript: Tirelli F, Grieco M, Biondi A, Belia F, Persiani R

\section{Availability of data and materials}

Not applicable.

\section{Financial support and sponsorship}

None.

\section{Conflicts of interest}

All authors declared that there are no conflicts of interest.

\section{Ethical approval and consent to participate}

Not applicable

\section{Consent for publication}

Not applicable

\section{Copyright}

The Author(s)2021

\section{REFERENCES}

1. Roy A, Crawford JM, Finegold MJ. Inherited metabolic and developmental disorders of the pediatric and adult liver. In: Odze RD, Goldblum JR, editors. Surgical Pathology of the GI Tract, Liver, Biliary Tract and Pancreas, Third Edition. Philadelphia: Elsevier 2015. p. $1475-538$.

2. Arya SV, Das A, Singh S, Kalwaniya DS, Sharma A, Thukral BB. Technical difficulties and its remedies in laparoscopic cholecystectomy in situs inversus totalis: A rare case report. Int J Surg Case Rep 2013;4:727-30. DOI PubMed PMC

3. Phothong N, Akaraviputh T, Chinswangwatanakul V, Trakarnsanga A. Simplified technique of laparoscopic cholecystectomy in a patient with situs inversus: a case report and review of techniques. BMC Surg 2015;15:23. DOI PubMed PMC

4. Kono Y, Ishizawa T, Tani K, et al. Techniques of fluorescence cholangiography during laparoscopic cholecystectomy for better delineation of the bile duct anatomy. Medicine (Baltimore) 2015;94:e1005. DOI PubMed PMC 
5. Pesce A, Piccolo G, La Greca G, Puleo S. Utility of fluorescent cholangiography during laparoscopic cholecystectomy: a systematic review. World J Gastroenterol 2015;21:7877-83. DOI PubMed PMC

6. Fernandes MN, Neiva IN, de Assis CF, Meguins LC, Fernandes MN, Meguins EM. Three-port laparoscopic cholecystectomy in a Brazilian Amazon woman with situs inversus totalis: Surgical approach. Case Rep Gastroenterol 2008;2:170-4. DOI PubMed PMC

7. Rungsakulkij N, Tangtawee P. Fluorescence cholangiography during laparoscopic cholecystectomy in a patient with situs inversus totalis: a case report and literature review. BMC Surg 2017;17:43. DOI PubMed PMC

8. Malik FS, Butt UI, Khan WK, Bilal SM, Umar M, Umer S. Laparoscopic cholecystectomy in situs inversus totalis. J Coll Physicians Surg Pak 2019;29:1000-2. DOI PubMed

9. Tebala GD, Bond-Smith G. Indocyanine green fluorescence in elective and emergency laparoscopic cholecystectomy. A visual snapshot. Surg Technol Int 2020;37:69-71. PubMed 